\title{
Characterization of pyrolysis products derived from three biological wastes and their effect on plant growth and soil water retention
}

\author{
Laila Bouqbis ${ }^{(1)}$, Hans Werner Koyro ${ }^{(2)}$, Claudia Kammann ${ }^{(3)}$, Lalla Fatima Zohra \\ Ainlhout $^{(4)}$ Laila Boukhalef ${ }^{(5)}$ and Moulay Cherif Harrouni ${ }^{(6)}$ \\ (1, 4, 5 Polydisciplinary Faculty, Ibn Zohr University, Taroudant, Morocco) \\ (2, 3 Department of Plant Ecology, Justus-Liebig-University, Heinrich-Buff-Ring26-32, 35392, \\ Giessen, Germany) \\ (6) Hassan II Agronomic and Veterinary Institute, Agadir, Morocco
}

\begin{abstract}
Summary. Over two-thirds of Morocco can be classified as semiarid, arid and desert with low and variable rainfalls. While the country is subject to frequent drought, groundwater resources are predominantly consumed by irrigated agriculture leading to the depletion of water resources and degradation of soil quality. Application of bio-resources wastes to soils after pyrolysis process is well documented to help retain water and nutrients in soils. In this study, three bio-resources wastes derived from argan shells, wood chip, a blend of paper sludge and wheat husks are characterized for physical and chemical properties. To determine the potential impact of salt stress and toxic substances the second part of this study focused on the effect these bio-resources wastes have on germination of salad and barley respectively. The three bio-resources obtained from different biomass showed some unique properties compared to the soil, such as high electrical conductivity (EC), high content of $\mathrm{K}, \mathrm{Na}$ and $\mathrm{Mg}$, low content of heavy metals. Moreover, the water holding capacities increased with increasing application of bio-resources wastes. Concerning the phytotoxic tests, no negative effect was observed neither for salad (Lactuca sativa L.) nor for barley (Hordeum vulgare) indicating that the three bio-resources could be safely used for agriculture. Collectively, the use of these bio-resources wastes as a soil amendment is anticipated to increase both water and nutrient and could provide the potential for a better plant growth mainly in semiarid, arid and desert climatic conditions like the case of Morocco in which the agricultural practices reserve a majority of the water resources to be used for irrigation.
\end{abstract}

Key words: bio-resources wastes, water retention, phytotoxic tests, plant growth.

\footnotetext{
* $\overline{\text { Corresponding author :bouqbisl@yahoo.fr }}$
} 


\section{Introduction}

In arid and semi-arid regions, availability of fresh water is one of the important factors that affects biological systems worldwide (Koyro et al., 2011; Gallardo et al., 2015). This is especially of importance where low rainfall imposes constraints on plant growth and development (Schlesinger et al., 2015, Abideen et al., 2017). The social demand on agriculture is not only to produce high-quality food for a growing world population but farming also has to deal with careful use of resources and the mitigation of climate change (von Glisczynski et al., 2016). The use of biochar (charcoal produced from biomass by pyrolysis in a low-oxygen environment for use as a soil amendment or carbon sequestration) as a soil amendment could help to achieve all these requirements. Biochar is attracting recently growing interest for its potential use as a carbon sequestration agent and as a soil amendment for improved agricultural productivity (Lehmann et al., 2006; Shackley et al., 2013; Sorrenti et Toselli., 2016; Forján et al., 2017). The ability of biochar to retain soil water is a function of the combination of its porosity and surface functionality (Suliman et al., 2017). Previous studies showed that soil properties such as water holding capacity (WHC), cation exchange capacity (CEC) and nutrient retention application of biochar can be affected positively by biochar treatment (Liu et al., 2012; Ventura et al., 2013, Forján et al., 2017).

However, the use of biochar is not without its critics. Research shows that biochar can contain dangerous inorganic contaminants and organic ones as well as dioxins and furans (Hale et al., 2012; Oleszczuk et al., 2013; Buss et Mazek., 2014; Kołtowski and Oleszczuk., 2015; Domene et al., 2015). In the case of high levels of contaminants there is a risk of their uptake by plants or migration down the soil profile to ground-waters. This may have negative effects for humans, for the environment and for living organisms. Thus, biochar applied to soils should be free of toxic substances before any future large-scale application. In this study, we determined the chemical and physical properties of two biochars obtained from commercial vendors in Germany from different wastes: Biochar I (BC I) derived from wood chip and biochar II (BC II) derived from a blend of paper sludge and wheat husks and their properties are compared to those of biochar produced in Morocco from argan shells (ASBC). Therefore, we investigated the effects these three biochars have on (i) germination of salad (test for salt stress) and (ii) barley (test for toxic substances) and the findings are compared to those obtained from argan shells biochar (test procedures are adapted from Busch et al., 2012).

\section{Materials and Methods}

\subsection{Soil, Peat and Biochar analysis}

All physical and chemical analysis were performed in the Hassan II Agronomic and Veterinary Institute (IAV) soil science laboratory. The $\mathrm{pH}$ and electrical conductivity (EC) were both measured in water extracts with standard electrodes. For chemical analysis, the total concentration of $\mathrm{Na}, \mathrm{K}, \mathrm{Ca}$ and $\mathrm{Mg}$ were determined by flame emission spectrophotometer and $\mathrm{Fe}, \mathrm{Mn}, \mathrm{Zn}$ and $\mathrm{Cu}$ by atomic absorption spectrophotometer and colorimetrically for $\mathrm{NaNO} 3$ and $\mathrm{KH} 2 \mathrm{PO} 4$.

\subsection{Water holding capacity}

Six biochar-fine sand mixtures have been prepared. We have used small amounts of biochar that equal $0,0.5,1,2,4$ and $8 \%$, which means that $1 \%$ describes a mixture of $1 \mathrm{~g}$ dry biochar with $99 \mathrm{~g}$ dry sand. Around $40 \mathrm{~g}$ of fresh weight of each mixture were filled in small gray PE-tubes (height: 5,5 cm; inner diameter: 3,6 cm) that were closed at the bottom with gaze and filter paper. The filled tubes were placed in a plastic box that was then filled with tap water. The box was covered with aluminum foil. After $24 \mathrm{~h}$ the tubes were placed 
on test tube racks to let water drip out. $24 \mathrm{~h}$ later, the weight of the tubes were determined and the water content was calculated (knowing in advance the dry weight of the substrate). Then, the maximum water holding capacity can be determined.

\subsection{Salad germination test}

The biochar was mixed with an inert, fine-sand medium and used in the salad germination test based on ISO 17126 (Busch et al., 2012), where the germination of a salt-sensitive species (Lactuca sativa L.) was evaluated. Several different proportions of biochar and fine sand were mixed following geometrical dilution. In accordance with the ISO test, the factor 2 is the maximal allowed, so the series used was: $0 \%$ (control), $0.5 \%, 1 \%, 2 \%, 4 \%$ and $8 \%$. For one replicate, an amount of fresh weight equal to $100 \mathrm{~g}$ of dry weight was taken out of the whole mixture and filled into a Petri dish. Tap water was added to set the water content to $85 \%$ of the maximum WHC. Forty seeds of Lactuca sativa L. were evenly sowed, leaving a free space of around $1 \mathrm{~cm}$ to the border of the Petri dishes. The seeds were pressed softly into the substrate. Afterward, $90 \mathrm{~g}$ (dry weight) of coarse sand was distributed on top. The prepared Petri dishes were placed open in a bloated, zippered plastic bag and positioned in the green house. For the first $48 \mathrm{~h}$, black plastic foil covered the dishes. After $5 \mathrm{~d}$ incubation, harvesting commenced and the number of germinated seedlings and the fresh and dry weights of the above ground biomass were determined. The Petri dishes, which still contained the soil mixture were mixed and $25 \mathrm{~g}$ of dry weight were taken. Around $100 \mathrm{ml}$ of water were added. After shaking for $1 \mathrm{~h}$ at $150 \mathrm{rpm}$, the substrate was allowed to settle for $30 \mathrm{~min}$ and then the $\mathrm{pH}$ and electrical conductivity (EC) were measured. All determinations were replicated three times.

\subsection{Barley germination test}

Five biochar-peat mixtures were prepared, using small amounts of biochar $(0 \%, 1 \%, 2.5 \%$, $5 \%$ and $10 \%$ ) where $1 \%$ describes a mixture of $1 \mathrm{~g}$ dry biochar with $99 \mathrm{~g}$ dry peat. Then, the dry weight and water holding capacity (WHC) of the substrates were determined. To prepare $1000 \mathrm{ml}$ of dry weight for every mixture, the amount of fresh weight of biochar and peat and the amount of water needed to set the mixture to $60 \%$ of the maximum water holding capacity (WHCmax) were calculated. Afterward, some textile/filter paper was placed into the bottom of the plant pots and the mixtures were split into four replicates while leaving sufficient to cover the seeds. After sowing 20 seeds of barely in every pot, the rest of the mixture was distributed over the seeds and the initial weight of the whole construction (pot + mixture with $60 \%$ of WHCmax + seeds) was recorded. The plots were then randomly placed in the greenhouse. The weight of each pot was recorded daily and the difference from the initial weight was made up by adding tap water. After $9 \mathrm{~d}$, the germination rate, biomass fresh weight and dry weight were determined.

\subsection{Statistical analysis}

For the barley and salad germination tests, the effects of different biochar additions on all replicated measurements were tested using one-way analysis of variance. The significance of differences among treatment groups was determined using the Tukey test. A result was considered significant at $\mathrm{p}<0.05$. All statistical tests were performed using the SigmaPlot 11 software (Systat Inc.; Chicago, IL, USA).

\section{Results and discussion}

\subsection{Soil, Peat and Biochar properties}

Several studies demonstrated that the environmental function of biochar in soil vary depending on the physical and chemical characteristics of the biochar which depend on feedstock used in the production of biochar and production conditions (Smider and Singh, 
2014; Sun et al., 2014; Nansubuga et al., 2015). The physical and chemical properties of three biochars compared to other media are presented in table 1.

Table 1. Properties of different biochars used in this experiment

\begin{tabular}{cccccc}
\hline & ASBC & BC I & BC II & Sand & Peat \\
\hline $\mathbf{p H}$ & 10,7 & 9,8 & 8,25 & 7,93 & 5,81 \\
$\mathbf{E C}\left(\mathbf{m i l l i S ~ c m} \mathbf{~}^{-\mathbf{1}}\right)$ & 4,83 & 1,25 & 1,33 & 0,48 & 0,94 \\
$\mathbf{K}(\mathbf{p p m})$ & 1906,25 & 521,73 & 421,87 & 7,11 & 78,26 \\
$\mathbf{N a}(\mathbf{p p m})$ & 339,2 & 46,54 & 242,85 & 3,47 & 257,94 \\
$\mathbf{C a}(\mathbf{p p m})$ & 4,8 & 0,61 & 0,6 & 34,09 & 190,9 \\
$\mathbf{M g}(\mathbf{p p m})$ & 1258,92 & 1303,73 & 1299,1 & 222,89 & 1191,58 \\
$\mathbf{F e}(\mathbf{p p m})$ & 0 & 0 & 0 & 9,07 & 0 \\
$\mathbf{M n}(\mathbf{p p m})$ & 0,04 & 0,083 & 0,02 & 7,7 & 0,14 \\
$\mathbf{C u}(\mathbf{p p m})$ & 0 & 0 & 0,062 & 1,3 & 0,06 \\
$\mathbf{Z n}(\mathbf{p p m})$ & 0,04 & 0,0042 & 0,04 & 0,42 & 0,04 \\
$\mathbf{N a N O}_{\mathbf{3}}(\mathbf{p p m})$ & 100 & 100 & 2666,66 & 100 & 133,33 \\
$\mathbf{K H}_{\mathbf{2}} \mathbf{P O} \mathbf{O}_{\mathbf{4}}(\mathbf{p p m})$ & 0,33 & 0,46 & 1,93 & 1 & 2,33 \\
\hline
\end{tabular}

The $\mathrm{pH}$ ranged from 5,81 to 10,7 and was higher in argan shells biochar. Depending on the pyrolysis conditions and the nature of the feedstock, different $\mathrm{pH}$ values ranging in $\mathrm{pH}$ from 4 to 13 can be reached (Chan et al., 2008; Sigua et al., 2016). In this sense, BC I, BC II and argan shells biochar resulted in the same $\mathrm{pH}$ range. The alkaline nature of all biochars has been reported to be useful to increase the $\mathrm{pH}$ of acidic soils.

The EC value was lower for sandy soil than for the other media, and was higher for argan shells biochar. Previous research reported that added biochar with high EC value into soil with low EC value (indicating its low salinity) increased EC of soil (Chan et al., 2008; Sigua et al., 2016). Thus, we would expect that the EC of the soil $(0,48 \mathrm{mS} / \mathrm{cm})$ would increase with biochar application.

Mineral composition differed among the substrates. The cation concentrations except $\mathrm{Ca}$ were the highest with different biochars and the lowest with sandy soil while $\mathrm{Ca}$ concentration was the highest with argan shells biochar and the lowest with biochar I and biochar II. The $\mathrm{Mg}$ content was relatively higher in the three biochars than $\mathrm{Ca}$ and $\mathrm{Na}$. It is reported that the chemical constituents of biochar are directly affected by different parameters: the temperature, the time and the heating rate during pyrolysis (Lima and Marshall, 2005) which is in line with our result. Furthermore, ASBC, BC I and soil showed the same value of NaNO3; whereas BC II had the higher value (Table 1). For KH2PO4, BC II and peat showed the higher value. Biochar, as reported by Coates, 2000, contain little or no NO3-, which is an essential nutrient for plant growth while the PO43- was characteristic for each feedstock (Uras et al., 2012). Given the high nutrient content of the three biochars, a significant positive effect on plant growth especially in the sandy soil was expected. However, previous studies showed that biochar can contain dangerous inorganic contaminants and organic ones (Hale et al., 2012; Oleszczuk et al., 2013; Buss et Mazek., 2014; Kołtowski and Oleszczuk., 2015). Heavy metal contents were characteristic for each feedstock, but generally increased after pyrolysis and with pyrolysis temperature. This was not the case in our study where heavy metal contents were higher with soil and lower with biochars. The three biochars used in this study contain more major nutrients and less heavy 
metals than the soil. These properties of biochars make them more attractive as a soil amendment agent.

\subsection{Water holding capacities}

For argan shells biochar, the water holding capacities were $0.36,0.39$ and $0.43 \mathrm{gH} 2 \mathrm{O} \mathrm{g}-1$ soil (dry weight) in $0 \%, 0.5 \%$ and $8 \%$ biochar-sand mixtures, respectively. The biochar application increased the WHC by $7,69 \%$ and $16,28 \%$ compared to the control. For BC I, the water holding capacities were $0.30,0.33$ and $0.51 \mathrm{gH} 2 \mathrm{O}$ g- 1 soil (dry weight) in $0 \%$, $0.5 \%$ and $8 \%$ biochar-sand mixtures, respectively. The biochar application increased the WHC by $10 \%$ and $70 \%$ compared to the control. For BC II, the water holding capacities were $0.30,0.32$ and $0.42 \mathrm{gH} 2 \mathrm{O} \mathrm{g}-1$ soil (dry weight) in $0 \%, 0.5 \%$ and $8 \%$ biochar-sand mixtures, respectively. The biochar application increased the WHC by $9 \%$ and $43 \%$ compared to the control. The biochar application increased the WHC by $70 \%, 43 \%$ and 16,28 for BC I, BC II and argan shells biochar, respectively indicating that the most important value was observed for BC I. An increase in water holding capacity has also been reported for wet conditions with biochar application (Abel et al., 2013).

\subsection{Salad Germination Test}

Our results, as shown in Fig. 1A, revealed a positive effect of ASBC, BC I and BC II on germination rate of salad in all of the biochar treatments except for the mixture with $4 \%$ of biochar I in which a non-significant decrease was observed. In other words, with the highest application, biochar increases the germination rate by $50 \%, 21 \%$ and $17 \%$ for ASBC, BC II and BC I respectively indicating that the most important value was observed for ASBC. A positive effect was also observed for the more sensitive parameter to biotoxic substances in biochar: fresh weight of seedlings (Fig. 1B and Fig. 1C). Even when the biochar contributed $8 \%$ of the volume of the germination mixture, no negative effect was observed. In other words, the biochar application increases the fresh weight per Petri dish (Fig. 1B) by $145 \%, 98 \%$ and $76 \%$ for BC II, BC I and ASBC respectively indicating that the most important value was observed for BC II. Moreover, the biochar application increases the fresh weight per plant (Fig. 1C) by $101 \%, 70 \%$ and $40 \%$ for BC II, BC I and ASBC respectively indicating that the most important value was observed for BC II. Collectively, our results indicate that biochar feedstock materials vary in their characteristics (e.g., pH, EC, nutrient levels) which also influence application rate and germination results. Thus before any large scale application, it is necessary to determine which biochar materials are best suited for application and at which rates to specific soils. 

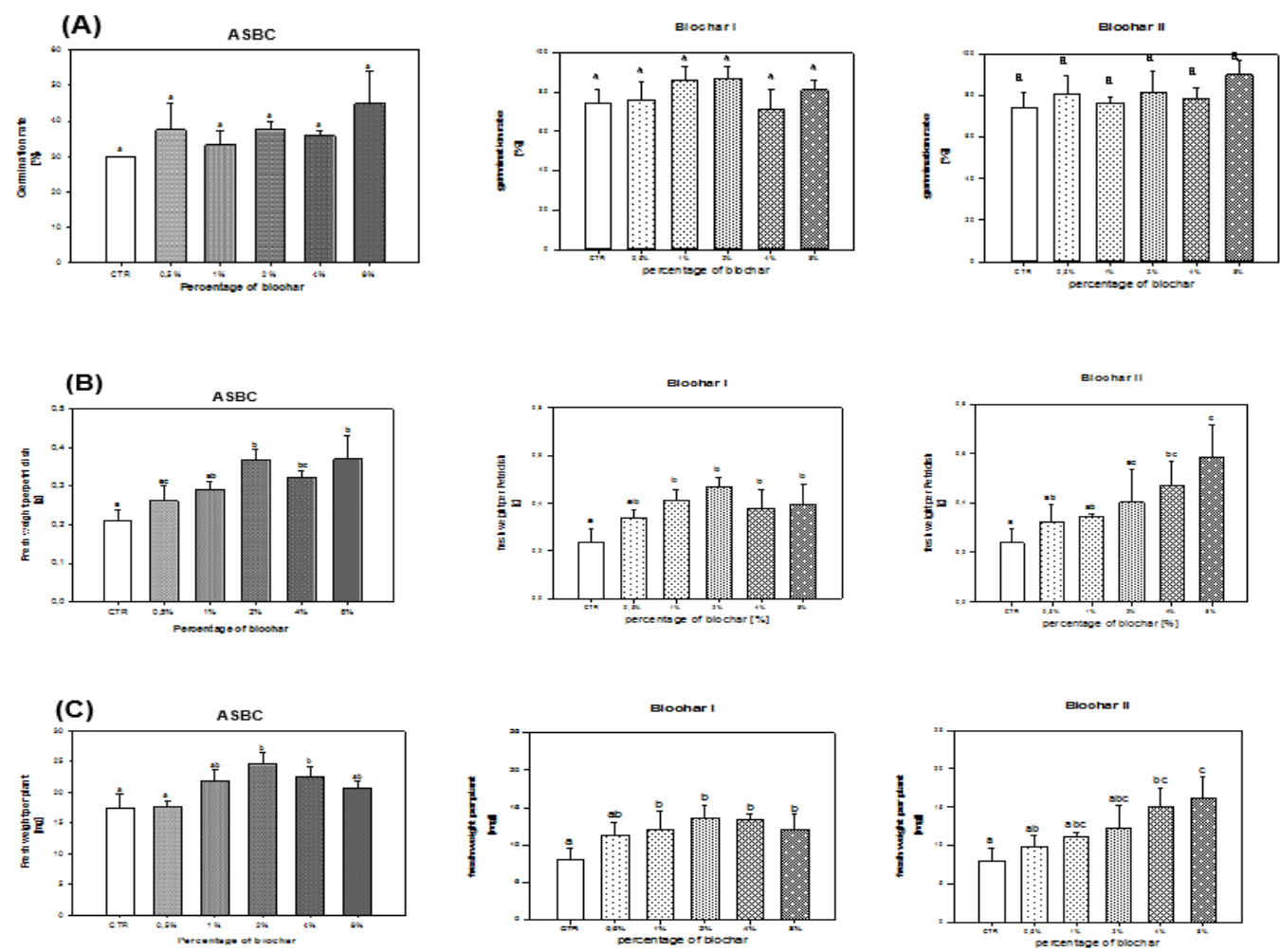

Fig.1. Salad germination test results: (A): germination rate, (B): fresh weight per Petri dish, (C): fresh weight per plant of three repeated test runs. The graphs present mean values and error bars present the standard deviation of the mean $(n=3)$. Different letters indicate significant differences (one-way analysis of variance, ANOVA) between different mixtures with biochar and the control

\subsection{Barley Germination Test}

In all biochar treatments $(1,2.5,5 \%$ and $10 \%$ biochar-peat mixture), no negative effect of the three biochars on germination rate of barley has been revealed (Fig. 2A). The same result was observed for the more sensitive parameters to biotoxic substances in biochar: fresh and dry weight of seedlings (Fig. 2B and Fig. 2C). In other words, biochar application increases the fresh weight by $14 \%, 7 \%$ and $7 \%$ for ASBC, BC I and BC II respectively indicating that the most important value was observed for argan shells biochar. Furthermore, biochar application increases the dry weight by $13 \%, 6 \%$ and $3 \%$ for ASBC, BC I and BC II respectively indicating that the most important value was observed for argan shells biochar. The low increases of biomass with biochar application could be due to much shorter test (9 days). Regarding the chemical properties of the ASBC, BC I and BC II compared to the peat (high content of $\mathrm{K}, \mathrm{Na}$, and $\mathrm{Mg}$, low content of heavy metals as presented in Table 1), the observed increases, even low, in fresh and dry weight of biomass could be the results of high level of water soluble nutrients in mixture with biochar application. Thus the three biochars could provide the potential for a better plant growth. 

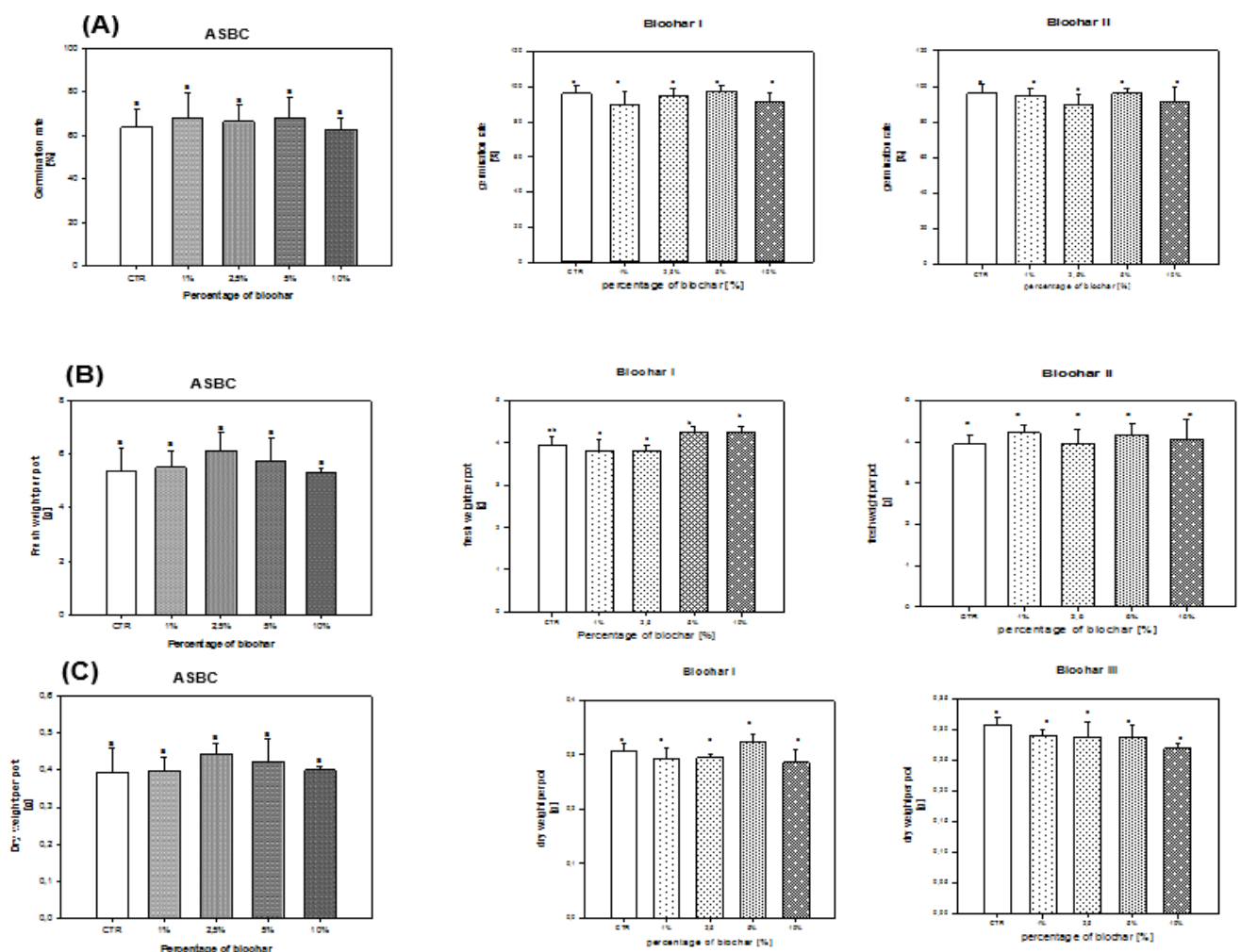

Fig.2. Effect of three biochars on germination of barley. (A): germination rate, (B): fresh weight per plant and (C): dry weight per plant for four repeated test runs. The graphs present mean values and error bars present the standard deviation of the mean $(n=4)$. Different letters indicate significant differences (one-way analysis of variance, ANOVA) between different mixtures with biochar and the control

\section{Conclusion}

The major reason of degradation in existing agricultural land is due to various abiotic factors including drought. The use of organic amendments like biochar has the advantage to increase soil organic carbon, soil aggregation and water retention capacity. In this study, the three biochars obtained from different biomass showed some unique properties compared to the soil, such as high $\mathrm{EC}$, high content of $\mathrm{K}, \mathrm{Na}$ and $\mathrm{Mg}$, low content of heavy metals. In addition, the results obtained from the two phytotoxicity test (test for salt stress and test for toxic substances) revealed no negative effect of the three biochars which provide a preliminary indication that they could be safely used for agriculture. When the three biochars are used in mixture with sandy soil, they increase the water holding capacities and the most important value was observed for biochar I. Thus, the use of agran shells biochar, Biochar I and biochar II as a soil amendment will be anticipated to increase both nutrient and water retention. 


\section{References}

H. W. KOYRO, M. A. KHAN and H. LIETH (2011): Halophytic crops: a resource for the future to reduce the water crisis?. Em J Food Agric. 23: 1-16

B. GALLARDO, A. ZIERITZ, D. C. ALDRIDGE (2015): The importance of the human footprint in shaping the global distribution of terrestrial, freshwater and marine invaders. PloS one. 10: 1-17

W. H. SCHLESINGER, M. C. DIETZE, R. B. JACKSON, R. P. PHILliPS, C. C. RHOADES, L. E. RUSTAD, J. M. VOSE (2015): Forest biogeochemistry in response to drought. Glob Change Biol. 22: 2318-2328

Z. ABIDEEN, H.W. KOYRO, B. HUCHZERMEYER, B. GUL AND M.A. KHAN (2017): Impact of a Biochar or a Compost-Biochar Mixture on Water relation, Nutrient uptake and Photosynthesis of Phragmites karka. Pedosphere. doi:10.1016/S10020160(17)60362-X

F. VON GLISCZYNSKI, A. SANDHAGE-HOFMANNA, W. AMELUNGA, R. PUDE (2016): Biochar-compost substrates do not promote growth and fruit quality of a replanted German apple orchard with fertile Haplic Luvicsol soils. Scientia Horticulturae 213: 110-114

G. SORRENTI, M. TOSELLI (2016): Soil leaching as affected by the amendment with biochar and compost. Agriculture, Ecosystems and Environment 226: 56-64

R. FORJÁN, A. RODRÍGUEZ-VILA, B. CERQUEIRA, E.F. COVELO (2017):

Comparison of the effects of compost versus compost and biochar on the recovery of a mine soil by improving the nutrient content. Journal of Geochemical Exploration. 183: $46-57$

W. SULIMAN, J.B. HARSH, N.I. ABU-LAIL, A.M. FORTUNA, I. DALLMEYER AND M. GARCIA-PÉREZ (2017): The role of biochar porosity and surface functionality in augmenting hydrologic properties of a sandy soil. Sci. Total Environ. 574: 139-147

J. LIU, H. SCHULZ, S. BRANDL, H. MIEHTKE, B. HUWE AND B. GLASER (2012): Short-term effect of biochar and compost on soil fertility and water status of a Dystric Cambisol in NE Germany under field conditions. J. Plant Nutr. Soil Sci. 175: 698-707

M. VENTURA, G. SORRENTI, P. PANZACCHI, E. GEORGE AND G. TONON (2013) : Biochar reduces short-term nitrate leaching from a horizon in an apple orchard. J. Environ. Qual. 42: 76-82

S.E HALE, J. LEHMANN, D. RUTHERFORD, A.R. ZIMMERMAN, R.T. BACHMANN, V. SHITUMBANUMA, A. O'TOOLE, K.L. SUNDQVIST, H.P.H. ARP AND G. CORNELISSEN, G. (2012): Quantifying the total and bioavailable polycyclic aromatic hydrocarbons and dioxins in biochars. Environ. Sci. Technol. 46 :2830-2838

P. OLESZCZUK, I. JO_SKO AND M. KU_SMIERZ (2013): Biochar properties regarding to contaminants content and ecotoxicological assessment. J. Hazard. Mater. 260: 375382 
W. BUSS AND O. MASEK (2014): Mobile organic compounds in biochar : A potential source of contamination-Phytotoxic effects on cress seed (Lepidium sativum) germination. Journal of Environmental Management 137: 111-119

M. KOŁTOWSKI AND P. OLESZCZUK (2015): Toxicity of biochars after polycyclic aromatic hydrocarbons removal by thermal treatment. Ecological Engineering 75: 79-85

X. DOMENE, A. ENDERS, K. HANLEY, J. LEHMANN (2015): Ecotoxicological characterization of biochars: Role of feedstock and pyrolysis temperature. Science of the Total Environment 512-513: 552-561

D. BUSCH, C. KAMMANN, L. GRÜNHAGE AND CHRISTOPH MÜLLER (2012): Simple Biotoxicity Tests for Evaluation of Carbonaceous Soil Additives: Establishment and Reproducibility of Four Test Procedures. Journal of Environmental Quality 41:1023-1032

B. SMIDER and B. SINGH (2014): Agronomic performance of a high ash biochar in two contrasting soils," Agriculture Ecosystems and Environment 191: 99-107

Y. SUN, B. GAO, Y. YAO, J. FANG, M. ZHANG, Y. ZHOU, H. CHEN, L. YANG (2014): Effects of feedstock type, production method, and pyrolysis temperature on biochar and hydrochar properties," Chemical Engineering Journal 240: 574-578

I. NANSUBUGA, N. BANADDA, F. RONSSE, W. VERSTRAETE, K. RABAEY (2015): Digestion of high rate activated sludge coupled to biochar formation for soil improvement in the tropics, " Water Research 81: 216-222

K.Y. CHAN, L. VAN ZWIETEN, I. MESZAROS, A. DOWNIE, S. JOSEPH (2008): Using poultry litter biochars as soil amendments," Australian Journal of Soil Research 46: 437-444

G.C. SIGUA, J.M. NOVAK, D.W. WATTS, M.G. JOHNSON, K. SPOKAS (2016): Efficacies of designer biochars in improving biomass and nutrient uptake of winter wheat grown in a hard setting subsoil layer," Chemosphere 142: 176-183

I.M LIMA AND W.E. MARSHALL (2005): Granular activated carbons from broiler manure: physical,chemical and adsorptive properties. Biores. Techno 96: 699-706

Ü. URAS, M. CARRIER, A. G. HARDIE, J. H. KNOETZE (2012): Physico-chemical characterization of biochars from vacuum pyrolysis of South African agricultural wastes for application as soil amendments. Journal of Analytical and Applied Pyrolysis 98: 207-213

S. ABEL, A. PETERS, S. TRINKS, H. SCHONSKY, M. FACKLAM, G. WESSOLEK (2013): Impact of biochar and hydrochar addition on water retention and water repellency of sandy soil. Geoderma 202:183-191 